\title{
OPTIMIZATION OF THE COMPOSITION OF WITHOUT CLINKER COMPOSITE GYPSUM-LIME BINDER
}

\author{
Bohdan Chekanskyi ${ }^{1}$, Iryna Lutsyuk
}

1. Department of Chemical Technology of Silicate Material, Lviv Polytechnic National University, UKRAINE, Lviv, 12 Bandera str., E-mail: chbb1992@gmail.com, ira_lutsuk@ukr.net

\begin{abstract}
- in order to optimize the content of metakaolin and amorphous silica in the composition of without clinker composite gypsum-lime binder the method of mathematical planning of the experiment was used. It was established that the maximum value of a compressive strength is achieved for the content of metakaolin 5.00\% and amorphous silica $-3.75 \%$.
\end{abstract}

Keywords - gypsum, quicklime, metakaolin, amorphous silica, compressive strength, normal density, curing, water resistance.

Recently, materials based on gypsum raw materials are widely used in construction due to low production energy costs. However, gypsum materials without modifying additives have low strength and water resistance [1]. One of the ways to increase the strength and water resistance of gypsum compositions is the introduction of quicklime and active mineral additives - metakaolin and amorphous silica.

To determine the optimal composition of the composite binder the mathematical planning with the use of two-factor experiment was carried. For changings of prescription levels of optimization (the amount of metakaolin and amorphous silica) the constant were the gypsumquicklime ratio (1.5:1.0), the sum of all components (100\%), the water-powder ratio $(\mathrm{W} / \mathrm{P}=0.80)$ and the temperature of the mixing water $\left(\mathrm{T}=8-12{ }^{\circ} \mathrm{C}\right)$. As a chemical additive, a borax $\mathrm{Na}_{2} \mathrm{~B}_{4} \mathrm{O}_{7} \cdot 5 \mathrm{H}_{2} \mathrm{O}$ was used in the amount of $0.5 \%$.

It was defined by the analysis of the obtained mathematical dependencies that the use metakaolin in the amount of 3.5-6.5\% and amorphous silica in the amount of 1.9-5.6\% makes it possible to obtain a stone with a compressive strength 9.25-9.50 $\mathrm{MPa}$ (fig. 1).

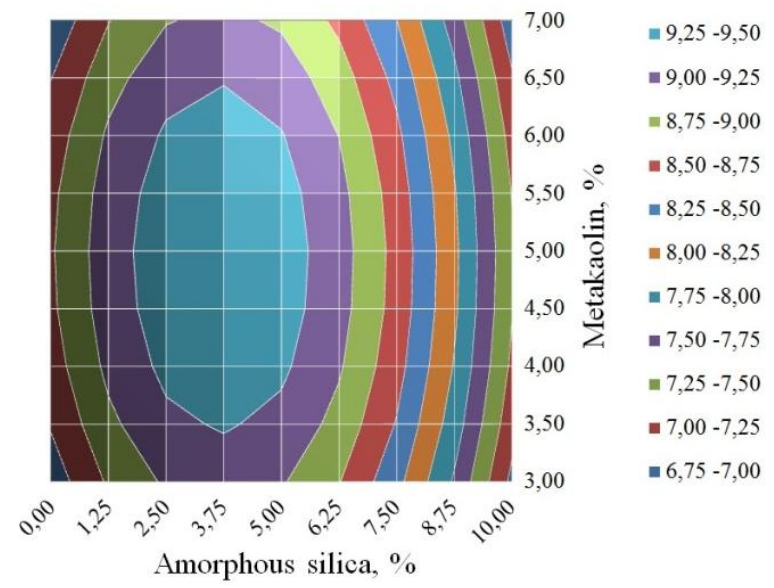

Fig.1. Isoparametric lines of influence of metakaolin and amorphous silica contents on the strength of gypsum-lime stone at the age of 28 days

For optimized binder composition the normal density ND and curing time was defined: $\mathrm{ND}=65 \%$, curing beginning - not earlier than 10 minutes, curing ending - no later than 15 minutes. Stone based on an optimized gypsum-lime binder is characterized by increased compressive strength of up to $35 \%$ herewith water resistance is $0.57 \%$.

[1] M. I. Khaliullin, A. R. Gaifullin, "Waterproof clinker-free composite gypsum knitting with additives of industrial wastes", News of the KSUAE, no. 3 (17), 157-165, 2011. 